\title{
L.A.S. Johnson: taxonomist, ecologist, conservationist ... botanist sens. lat.
}

\author{
Doug Benson
}

\begin{abstract}
Benson, D.H. (National Herbarium of New South Wales, Royal Botanic Gardens, Mrs Macquaries Road, Sydney, NSW, Australia 2000) 1996. L.A.S. Johnson: taxonomist, ecologist, conservationist ... botanist sens. lat. Telopea 6(4): 521-526. A brief account of the contribution of L.A.S. Johnson to the fields of ecology and conservation, during his research career and as Director of the Royal Botanic Gardens Sydney, is given.
\end{abstract}

\section{Introduction}

As Director of the Royal Botanic Gardens Sydney, and throughout his research career, Dr L.A.S. Johnson has had wide botanical interests, and his particular concern for the environment and its conservation has been evident to those who have worked with him. His contribution to taxonomy may be immense, but his broader views of plants and their ecological context, plants in the landscape, the uniqueness and importance of the Australian landscape, and of conservation issues broadly, have been woven into his writing, and are evident in his public and scientific life.

With his appointment as a taxonomist (Assistant Botanist) at the Royal Botanic Gardens in 1948 Johnson began a long and productive scientific career that was to concentrate on systematic botany; this has always dominated his scientific output. However during his final years at Sydney University he had been influenced by the ecologist Noel Beadle (then lecturer and interested in the role of soil nutrients in determining vegetation patterns), and developed an interest in geomorphology, ecology and landscape.

\section{Plants and their ecological context}

Although his taxonomic interests are many, the eucalypts have been a major component of Johnson's work. Eucalypts form the dominant cover for much of the Australian landscape, particularly in New South Wales, and an understanding of their distribution requires more than an assessment of herbarium specimens - it requires a feel for, and. knowledge of, the landscape and the local habitats within it. In A Classification of the Eucalypts, Pryor \& Johnson (1971) draw upon 'information from the associated disciplines of genetics, ecology, and anatomy as well as amplifying the study of morphology along traditional lines' (p1). The variation patterns characteristic of different kinds of species or complexes subsequently described are strongly related to geographic distribution and broad landscape characteristics. In assessing the distinctiveness of the subgenera Johnson (pers. comm.) argues that there are basic ecological differences between them and that the predominance of a particular subgenus relates to differences in the nutrient content of the soils - Symphyomyrtus species are most widespread on fertile soils while Monocalyptus are more common on the least fertile soils [the importance of soil fertility is a recurring and unifying theme throughout his work]. This is evidently the case for vegetation on the western Blue Mountains (Benson \& Keith 1990) - [the broader picture was pointed out daily to the author during a crosscontinental fieldtrip with LASJ in 1984]. 
Similarly in his studies of the Casuarinaceae Johnson notes previously undescribed ecological differences at the generic level. His new genus Allocasuarina, is 'usually on soils markedly deficient in nutrients' (Johnson 1982), whereas Casuarina, at least in Australia, occurs on the more fertile soils (LASJ pers. comm.).

\section{Implications for biodiversity conservation}

Plant systematics is a key component in the identification and conservation of biodiversity. Recognition of taxa and the variation within taxa is necessary if adequate conservation of biodiversity is to be achieved. Systematic work such as that of Johnson provides assessments of the extent of variation within and between populations how revisions of certain groups have been made affects the way plant communities have been described and species conserved.

For example, the number of eucalypt species recognised has increased from about 450 in 1971 to $800-900$ in 1995, as a result of the work of Johnson and others in the 1980s and $90 \mathrm{~s}$. The increasing number of species has been partly due to the discovery of many previously unknown species in remote areas as well as in some frequented places [despite a 1971 prediction by Pryor \& Johnson that 'It is likely that relatively few taxa still await discovery as a result of exploration in relatively little-known areas'].

The increased number has also been due to an increasing focus on previously described species. Johnson's eucalypt research includes extensive reassessment of formerly accepted species and their subdivision into new taxa (mostly species). He has always been interested in the importance of recognising areas of variation and potential genetic diversity within taxa, often leading to the recognition of many species within former large groups. He regards ecological aspects, including habitat, soil type, nutrient levels, drainage, geographical distribution etc as important contributory data in determining the distinctiveness of taxa. By considering aspects such as geographic isolation and local habitat, Johnson highlights the variation within previously broadly-defined species and separates them into separate species. Species recognised by Johnson include the mallee ashes, Eucalyptus dendromorpha, E. rupicola (Johnson \& Blaxell 1972) and E. laophylla (Hill \& Johnson 1991); Eucalyptus dorrigoensis, previously a subspecies of Eucalyptus benthamii, Angophora crassifolia, previously a subspecies of A. bakeri, and Angophora euryphylla, a subspecies of A. costata (Johnson \& Hill 1990). Formal systematic recognition of variation makes its overall conservation achievable, as conservation strategies to protect each species (the most frequently used unit of biodiversity) can then be established. Of the 70 taxa of Eucalyptus and Angophora on the national Rare or Threatened Australian Plants list (ROTAP) 41 have Johnson as author or coauthor.

L.A.S. Johnson has always been prepared to argue for the protection of occurrences of localised rare species. He encouraged the author to recommend the protection of Eucalyptus benthamii at Bents Basin (subsequently Bents Basin State Recreation Area), for example, and personally took up the case for a small area of Allocasuarina diminuta at Kingsford. He has also been a strong advocate for recognising the importance of conserving examples over the whole of species' distributional range including geographical extremes.

\section{Plants in their landscape}

Perhaps L.A.S. Johnson's most perceptive ecological insights are in his work on the sclerophyllous flora, doubtless influenced by Noel Beadle's work (for example Beadle 1954). Because Johnson's ecological contributions have been included as often-incidental 
comments in papers and journals devoted primarily to systematic botany they have been overlooked by many ecologists [much to the exasperation of LASJ]. In studies on Proteaceae Johnson discusses the importance of soil fertility in the evolution of the flora and argues that the characteristics of the scleromorphs are associated with survival in nutrient-deficient situations and only to a lesser degree with climatic stress. Johnson \& Briggs (1981) take up the history of the scleromorphic floras in terms of world distribution, ecogeography and the development of sclerophyll communities based on their studies on the Myrtaceae, Proteaceae and Restionaceae ('three old southern families'). They argue that the low-nutrient (and chiefly scleromorphic) floras and the various floras on moderate- or high-nutrient substrates remained highly distinct since their differentiation, perhaps as early as the Palaeogene. There was further modification by additional speciation under the mediterranean climate in south-western Australia, and in eastern Australia under less regular periods of drought. Some low-nutrient scleromorphs penetrated the edaphically poorer parts of the newly-expanded arid regions. A salient point that Johnson \& Briggs make is that 'with very few exceptions, they [the low-nutrient scleromorphs] did not spread into the adjacent moderate- or high-nutrient areas' [their emphasis].

His passionate interest in low-nutrient scleromorphic vegetation led Johnson to recognise the importance of eutrophication as a major factor in weed invasion along creeks in Sydney sandstone areas in 1970s, at the same time as others (Don Adamson of Macquarie University, Eileen and Joan Bradley, initiators of bush regeneration strategies) were calling for action.

'On the local front, resist by all legal means the unnecessary fouling of gullies by residential or other development at their heads, leading to mineral enrichment and choking by weeds.' he wrote in the Preface to Flowers and plants of New South Wales and Southern Queensland (Rotherham et al. 1975). 'Resist "reclaiming" (a profoundly dishonest word) of swamps. Prevent building on headlands and unnecessary artificial revegetation of sand-dunes. Oppose clearing, mowing, planting of roadsides; let the native vegetation or even harmless "weeds" grow - they will support a rich life of invertebrate animals and some birds and other vertebrates (though certain noxious weeds cannot be tolerated and harbour for rabbits must sometimes be destroyed). Keep even the smallest patches of native or semi-native vegetation - the large reserves alone are not enough.'

\section{The uniqueness and importance of the Australian landscape}

His ecological interests are probably expressed most strongly in his commitment to conservation. He stressed the importance of retaining roadside remnants in the 1960s, raising concerns that would become mainstream in the 1990s in the work of organisations such as Greening Australia and Landcare*. 'Large areas of the Australian landscape derive much of their character from trees that are survivors from forests or woodlands previously existing in areas now mainly cleared. Many of these trees are already old, and grazing and cultivation are preventing natural establishment of their progeny' wrote Johnson \& Briggs in 1971 in an article on Unplanted trees: the value of natural regrowth. They argued that natural regeneration not only provided windbreaks and shelter but maintains the distinctive Australian character of the landscape and

* Many botanists have been concerned at the destruction of vegetation and loss of species. For example W. Woolls wrote in the late 1880 s of the loss of local biodiversity, while J.H. Maiden wrote much on the unnecessary destruction of forests and the degradation of rural land in the early 1900s. While the work of botanists may not have been directly influential in changing community attitudes, the results of their ongoing research do provide a solid basis for necessary action once the need for change is finally recognised. 
preserves scientifically valuable information about the pre-existing vegetation. They also emphasised the importance of using locally collected seed in revegetation projects to maintain local genetic provenances. The dieback of mature Eucalyptus trees in rural areas particularly in the New England area in the 1980s had an obvious and shocking impact on the rural landscape. Resulting from the cumulative effects of decades of rural activity and the failure to nurture regeneration, the loss of the natural species patterns was of particular concern to Johnson. He noted that the patterns of dieback were related to particular eucalypt groups and to particular soil types, mainly the most fertile soils with species of subgenus Symphyomyrtus. The trees on poorer soils were relatively unaffected. While the causes are more complex, involving weather conditions, insects, birds, pasture improvement and overclearing and grazing, the general ecological position was not grasped for some time, and Johnson was concerned at the further alteration of the landscape by those trying quick-fix solutions such as the planting of exotic conifers and non-local native trees. Johnson argued for further protection of remnant vegetation and the replanting with species not only native to the area, but collected from local seed sources to retain its local genetic identity.

A major issue for the expanding conservation movement in the 1960s was mineralsandmining on the North Coast which was destroying extensive areas of coastal heath and forest on low-nutrient soils, areas that had previously remained undisturbed and were seen as an important part of a new coastal national parks system then being proposed. Johnson was concerned to see that the scientific values of the vegetation were included in the debate. However, as a Division within the Department of Agriculture at the time, the Royal Botanic Gardens was restricted in the conservation issues it could pursue, input on such issues depending on the professional standing of individual officers. Johnson was able to provide scientific input as a member of the Committee of the New South Wales Government to Review National Parks, State Parks and Reserves in 1967 and subsequently on the Sim Committee (Committee of Inquiry on Differences and Conflicts between Interests of Parks and Conservation Authorities, Scientific Bodies and Mining Companies), but the committee work was frustrating. Though public support for environmental standards and conservation was rapidly growing worldwide and locally, it was still too weakly expressed to be a basis for firm action by many politicians. But the committees followed and overlapped conservation campaigns spearheaded by bushwalkers and helped to focus expression of community concerns. By the time the Sim Committee completed its work the community attitudes assumed at its start, at least by the mining industry representatives, could no longer be taken for granted. The Committee had helped to make obsolete the basis from which it had started.

\section{As Director}

At the end of his term as Director (1972-1985), Johnson described the Royal Botanic Gardens as being in the business of seeking and communicating an understanding of life' (Johnson 1985a). On the scientific side he had tried to broaden the traditional taxonomic base by encouraging biosystematic, palynological and phycological studies, and the increasing use of modern equipment such as the scanning electron microscope. He was also a strong advocate of fieldwork. In ecology he supported the two existing ecological staff and two additional assistants subsequently provided directly by the Public Service Board, but did not increase the ecological staff further as any additional staff would have been at the expense of systematic botany positions. He always considered that the prime function of the scientific section was systematic botany and indeed ensured that under the Royal Botanic Gardens and Domain Trust Act 1980, the Trust, in meeting its Principal objectives is also required to give particular emphasis 
to encouraging and advancing the study of systematic botany.' Whether this is too narrow a focus for the main scientific resources of the Royal Botanic Gardens over the longer term remains to be seen. With the increasing recognition of the importance of the conservation role of the Gardens and the evidence that Johnson was able to use ecological concepts and data to the benefit of his systematic studies, more emphasis on ecology may be an appropriate, and productive, future strategy.

L.A.S. Johnson strongly supported the publication of scientific work and was actively involved in setting up the Royal Botanic Gardens ecological journal Cunninghamia. After being moved from Agriculture to the Premier's Department in 1979, and with the increased autonomy provided by establishment of the Trust in 1980, the Gardens was free to take a more active role in broader issues. Johnson encouraged the organisation to submit views on the major environmental issues of the day, such as the conservation of rainforests, better land management in the Western Division, or recommendations of specific areas to be conserved. Occasionally he had to support his staff when senior officers in other sections of government were displeased where these views were contrary to the often short-sighted developments proposed by other departments.

\section{Conservation issues}

L.A.S. Johnson has always been concerned with broader conservation issues and in particular with the need to curb population growth and to 'respect man but do not worship him or the gods he has made in his image to favour his expansion at the world's expense'(Johnson 1975). In response to the ecological and environmental dangers posed by the conventional belief in the absolute necessity of continued economic growth, he has taken an active interest in non-growth steady-state economics (e.g. as proposed by Herman Daly, Louisiana State University).

'We need schools of economics freed of political preconceptions and antiquated ideas of left and right, which are now matters of minor import in our coming crisis. We need them to put their energies into seeking economic solutions that do not involve increasing or even maintaining GNP (gross national product).' (Johnson 1985b)

We live in a time in public administration when the perceived importance of the administrator and manager, frequently overrides the importance of expertise and insight. While organisations say the right things in mission statements, they fail to deliver because of budgetary constraints, priorities set wrongly or lack of understanding of science and its significance and needs (by managers with primarily administrative training). The senior person who actually believes in the worth of an organisation and its commitment, is to be valued. The Royal Botanic Gardens, and the wider community, have been fortunate to have had among its succession of directors a figure such as L.A.S. Johnson.

\section{References}

Beadle, N.C.W. (1954) Soil phosphate and the delimination of plant communities in eastern Australia. Ecology 35: 370-375.

Benson, D.H. \& Keith, D.A. (1990) The natural vegetation of the Wallerawang map sheet. Cunninghamia 2: 305-335.

Hill, K.D. \& Johnson, L.A.S. (1991) Systematic studies in the eucalypts - 3: New taxa and combinations in Eucalyptus (Myrtaceae). Telopea 4: 223-267.

Johnson, L.A.S. (1975) Preface, in Rotherham, E.R., Blaxell, D.F., Briggs, B.G. \& Carolin, R.C. (1975) Flowers and plants of New South Wales and southern Queensland (A.H. \& A.W. Reed: Sydney).

Johnson, L.A.S. (1982) Notes on Casuarinaceae II. Journal of the Adelaide Botanic Gardens 6: 73-87. 
Johnson, L.A.S. (1985a) Whence, where, whither? - the Royal Botanic Gardens in review. In Royal Botanic Gardens and Domain Trust Annual Report 1984-1985 (Royal Botanic Gardens Sydney). Johnson, L.A.S. (1985b) Learning in a botanic garden. Unpub. (Royal Botanic Gardens Sydney). Johnson, L.A.S. \& Blaxell, D.F. (1972) New taxa and combinations in Eucalyptus - 1. Contributions from the N.S.W. National Herbarium 4: 284-290.

Johnson, L.A.S. \& Briggs, B.G. (1971) Unplanted trees: the value of natural regrowth. Agricultural Gazette of New South Wales 34-35.

Johnson, L.A.S. \& Briggs, B.G. (1981) Three old southern families - Myrtaceae, Proteaceae and Restionaceae. In A. Keast (ed.), Ecological biogeography of Australia (Dr W. Junk: The Hague).

Johnson, L.A.S. \& Hill, K.D. (1990) New taxa and combinations in Eucalyptus and Angophora (Myrtaceae). Telopea 4: 37-108.

Pryor, L.D. \& Johnson, L.A.S. (1971) A classification of the eucalypts (Australian National University: Canberra).

Manuscript received 1 September 1995

Manuscript accepted 30 November 1995 